pretación y crítica de la obra, todo lo cual puede reducirse a los siguientes epígrafes:

1. La estructura formal de la obra. El cuerpo y las notas.

2. La serie de las categorías. Categorías a la vez superiores e inferiores. Categorías recurrentes y no recurrentes. El pensamiento circular en Hegel.

3. La terminología de Hegel y la traducción española de ella.

4. El método dialéctico.

5. Cómo presenta Hegel su Lógica. La Lógica como Aufhebung del pasado filosófico y de la ciencia contemporánea. En especial: Hegel y Aristóteles, Hegel y la matemática.

6. Las categorías como "conceptos" y como "objetos". Como categorías "generales" y como categorías de "el Universo". La Lógica como Metafísica. El idealismo objetivo.

7. El análisis ontológico de la realidad. El orden de investigación y el orden de exposición. La aporía de la distinción de lo fenoménico y lo no fenoménico en un sistema monista de lo fenoménico.

8. El lenguaje, la filosofía, el racionalismo, el idealismo y la Lógica.

9. La presencia de lo irracional en la Lógica.

10. La Fenomenología del Espíritu y la Lógica. La Lógica y el resto del sistema. La aporía del paso del pensamiento puro a la naturaleza y el espíritu en un sistema de idealismo absoluto.

11. El panteísmo juvenil de Hegel en la Lógica. Hegel y Spinoza.

12. Hegel y Kant. Teoría del Conocimiento y Metafísica. El pensar sintético. Las antinomías. El argumento ontológico. La esencia y la existencia en la Lógica.

13. Hegel y la filosofía actual. Lo vivo y lo muerto de la Lógica.

Es propósito del profesor y de los miembros del seminario más constantes y destacados recoger los resultados del trabajo del seminario en un volumen colectivo que podría servir en adelante de introducción al estudio de la Lógica, comprendiendo: una exposición de conjunto según los epígrafes anteriores; un análisis detallado de la obra; la traducción y el comentario de una serie de pasajes capitales y especialmente representativos; un vocabulario alemán-español explicado de la terminología de la obra.

\title{
SEMINARIO DE TESIS
}

La labor de este seminario en 1954 ha sido continuación de la de años anteriores. El seminario empezó a funcionar en El Colegio de México, pero para componer tesis destinadas a obtener los grados de maestro y doctor en Filosofía en la Facultad de Filosofía y Letras de la Universidad Nacional 
Autónoma de México, de acuerdo con un convenio entre ésta y El Colegio. El seminario se dedicó desde un principio al estudio de la historia del pensamiento y de las ideas en los países de lengua española: las tesis que se compusieran en él debían versar sobre temas de esta historia. Esta orientación de la labor del seminario se debió a dos razones cardinales. La historia del pensamiento y de las ideas en los países de lengua española presentaba un interés singular para fomentar la filosofía misma de estos países: el conocimiento más cabal posible de los antecedentes históricos de una filosofía es instrumento de ésta, dadas las relaciones corrientemente admitidas en la actualidad entre la filosofía en general y su historia. Por lo demás, parecía fundado hacer una distinción entre filosofía, pensamiento e ideas, o entre las respectivas historias. En los países de lengua española se habla de sus pensadores más bien que de sus filósofos. No simplemente porque se niegue la existencia de filósofos de lengua española en el sentido en que se afirma la de filósofos de otras lenguas: el reconocimiento de la existencia de los primeros en este sentido es creciente. Principalmente porque los filósofos de lengua española en los tiempos contemporáneos son parte de un conjunto de autores cuyas obras desbordan, por sus temas y géneros, de la filosofía stricto sensu: parte de la que se pasa al resto del conjunto sin solución de continuidad, aunque no fuese sino porque los más y más eminentes autores de obras filosóficas en dicho sentido son también autores de obras de los otros temas y géneros aludidos. Los conceptos de pensamiento y de historia del pensamiento tienen, pues, más extensión que los de filosofía e historia de la filosofía. Los de ideas e historia de las ideas son aún más extensos. Los pensadores son autores de obras, de publicaciones, y autores no sólo de nombre conocido, sino de más o menos renombre. Ideas las tienen los anónimos integrantes de todas las clases sociales, del pueblo, de las masas. La historia de las ideas no necesita entenderse como la de ciertas ideas privilegiadas, por la razón que sea: debe entenderse como la de las ideas dominantes en los grupos humanos que pueden distinguirse social e históricamente. Por otra parte, aconsejaban la preferencia por tesis versantes sobre temas de historia del pensamiento y de las ideas en nuestros países razones circunstanciales de algún peso: los conocimientos requeridos, de una parte, para la composición de tesis y poseídos efectivamente, de otra parte, por la generalidad de nuestros estudiantes de filosofía; los instrumentos bibliográficos disponibles corrientemente en nuestro medio. Finalmente, los temas doctrinales de tesis son más arriesgados que los históricos. La invención de ideas requiere una capacidad de la posesión de la cual no se puede estar seguro por adelantado. La investigación histórica laboriosa descubre siempre algo en la realidad histórica, que multiplica su detalle ante la mirada atenta; y el talento puede llevarla hasta cimas $u$ honduras émulas de las mayores doctrinales. 
Animado por las anteriores razones, inició el seminario sus tareas con la composición de $\mathrm{D}$. Leopoldo Zea de sus tesis de maestría y doctorado, respectivamente, El positivismo en México (1943) y Apogeo y decadencia del positivismo en México (1944). El positivismo era la filosofía dominante en el país durante el período inmediatamente anterior al que podía considerarse como estrictamente actual por ser el de los maestros vivos, aunque habían reaccionado justo contra él, en una obra de superación del mismo generalmente considerada, con fundamento, como lograda. Este proceso histórico pedía ya un estudio lo más perfecto posible del positivismo mexicano. A responder a la petición vinieron los dos volúmenes nombrados.

Del estudio del positivismo, el movimiento filosófico más importante de todo el siglo xIx en México, descendió el seminario al siglo xvin, en busca de la introducción de la filosofía moderna en el país, antecedente ideológico de su "revolución de independencia". Era lugar común que la introducción de la filosofía moderna en el país había sido la meritoria obra de Gamarra: este "discípulo de Descartes" había introducido, con la filosofía cartesiana, la moderna en México. Mas, por un lado, el estudio de la obra de Gamarra, emprendido por la señorita Victoria Junco, arrojó un resultado bastante diverso de las anteriores ideas corrientes, expuesto en la tesis Algunas aportaciones al estudio de Gamarra o el eclecticismo en México (1944). Gamarra no era un cartesiano, sino un ecléctico, un partidario de un eclecticismo olvidado por la Historia de la Filosofía, a pesar de ser un movimiento internacional de importancia histórico-cultural, si no puramente filosófica, desde fines del siglo xvi hasta fines del xvIII, por los que venía a empalmar con él el eclecticismo francés de la escuela de Cousin, éste sí bien conocido por la Historia de la Filosofía -como también el eclecticismo pagano y cristiano de fines de la Antigüedad, invocado precisamente como antecedente y modelo por el de los siglos xvI y xvIr. Por otro lado, desde 1941 el Dr. D. Gabriel Méndez-Plancarte había Ilamado de nuevo la atención sobre la obra de los jesuítas mexicanos desterrados en 1767 a Italia, sugiriendo la idea de que en la introducción de la filosofía moderna en México se habían adelantado a Gamarra. Este había sido discípulo de los jesuítas, y aquéllos habían intentado una renovación de la enseñanza inspirada por su conocimiento de la filosofía y la ciencia modernas. Todo lo anterior impulsó los trabajos del seminario en dos direcciones. El conocimiento más completo posible del pensamiento en México durante el siglo xvir exigía el mismo conocimiento del ambiente ideológico en general del país durante el siglo. Como copiosa fuente de conocimiento de la historiá de las ideas en México durante este período de ella se ofrecían los papeles de la Inquisición. La señorita Monelisa Lina Pérez-Marchand, utilizando sólo una porción bien escogida de la desbordante fuente, porción pequeña relativamente al todo, pero voluminosísima en sí misma, obtuvo los resultados con que compuso sus Dos etapas ideológicas del siglo xviii en México, a través de los papeles de la Inquisición (1945). La otra dirección de los trabajos del 
seminario fué la convergente de la introducción de la filosofía moderna en los países de lengua española y del eclecticismo de los siglos xvir y xvII en todos los países en que este movimiento se había desarrollado. Al trabajo en esta dirección respondieron La introducción de la filosofía moderna en México (1948), en que el señor Bernabé Navarro confirmó ampliamente la antes mentada sugestión debida a su maestro el Dr. Méndez Plancarte, y La introducción de la filosofía moderna en España (1949), de la señorita Olga Victoria QuirozMartínez.

Desde 1946 empezaron a sumarse a las anteriores direcciones de los trabajos del seminario otras nuevas. La que primero dió resultados fué la que extendió los trabajos a un primer caso de las corrientes ideológicas que se prolongan, con más o menos continuidad, a través de la historia entera de la cultura mexicana: el caso de la corriente asunto del libro Los grandes momentos del indigenismo en México (1950), de D. Luis Villoro. Hasta la de esta obra inclusivamente, las publicaciones del seminario habían sido de género histórico, obedientes a las razones expuestas al principio. Desde 1946 se intentó pasar de la pura Historia a investigaciones de otro tipo. La señorita Vera Yamuni emprendió la investigación de la forma o formas de pensar por las que parece que se considera pensadores, más corrientemente que filósofos, a los contemporáneos de lengua española. La empresa abrió desde un principio la perspectiva de una serie de volúmenes. El primero, con el título Conceptos - e imágenes en pensadores de lengua española, apareció en 1951. Y por él se empalma con las tesis del seminario en este año de 1954: una, por publicada durante él; las otras, por acabadas, continuadas o iniciadas durante él.

La publicada en él es La génesis de la conciencia liberal en México, de D. Francisco López Cámara. Al liberalismo corresponde en México una corriente ideológica tan importante como continua desde la revolución de independencia hasta el mismo día de hoy, con los antecedentes en el xvII, la exposición de los cuales constituye la primera parte del libro del señor López Cámara: "Tres expresiones de la conciencia criolla colonial". Las partes segunda y tercera se titulan, respectivamente: "El proceso pre-liberal de la Revolución de Independencia" y "Erosión y sentido de la conciencia liberal". La primera parte comprende estos tres capítulos: "El criollo como conciencia de clase", "El criollo como misión histórica", "El criollo como teórico de la Independencia". La segunda, estos dos: "La ideología insurgente", "La Iglesia y la transformación mental del insurgente". La tercera, estos otros dos: "Tránsito al liberalismo", "El sentido social e histórico de la conciencia liberal". Cada una de las tres partes concluye con una "Reflexión": "La emancipación del criollo y la modernidad mexicana del siglo xvm", "Criollos colonialistas y criollos insurgentes", "Revolución y Liberalismo". Cada uno de los capítulos abarca varios parágrafos, cuyos títulos se omiten por no cansar. Los títulos reproducidos pueden dar una idea, no sólo del contenido del libro, sino incluso de unos primeros aspectos de su método y de su alcance total. Los hechos ideológico- 
sociales se narran articulando la reconstrucción de su proceso histórico por medio de conceptos autóctonos, por decirlo así, de los hechos mismos tales cuales dados por las fuentes. Estas son en su totalidad directas: ampliamente más de un centenar de muy variadas publicaciones y documentos, en su gran mayor parte de la segunda decena del siglo xIx. Las ideas están tratadas como vehículo para llegar al resto de la realidad social de que son expresión. La narración histórica constituye así una explicación sociológica de las ideas. Pero la autoctonía de los conceptos en los hechos reconstruye el proceso de éstos en una sucesión de distinciones o diferenciaciones tan complejamente móviles como sin duda fueron los hechos mismos -son los hechos históricos en general. Lejos de empeñarse en reducir a un esquema escueto y rígido, se cuida de distinguir en simultaneidad y sucesión, conforme a las ideas de que la lógica más propia de la Historia no es la de la generalización, sino la de la diferenciación, y de que las parcelas de la historia no son menos complicadas que las almas de los individuos, en las que convive lo contradictorio. Ejemplos de tales distinciones, una bien conocida ya antes de esta publicación, la otra quizá mucho menos, la distinción entre criollos colonialistas y criollos insurgentes y la que hubo en la actitud de los eclesiásticos en relación con la independencia. El libro es, por su tema, de historia de las ideas más que de historia del pensamiento, porque los orígenes de la ideología liberal en México están en un ambiente ideológico difuso en ciertas capas de la sociedad mexicana, a cuyos portavoces no saca del anonimato histórico el figurar sus nombres al frente de sus publicaciones - de las que un número considerable es, por lo demás, anónimo-. Y el libro, por su método, es Historia tangente, cuando menos, a una filosofía de la historia de la que ofrece un buen ejemplo: no una filosofía de la historia en general, sino una interpretación filosófica de una porción concreta de la historia. El hecho de encontrarse ya el libro a la disposición del público excusa de insistir en la caracterización de él. Es de esperar que el señor López Cámara continúe su indagación histórica de la ideología liberal mexicana después de la justificada interrupción por su viaje de trabajo y estudios a Europa y el Oriente Medio.

De las tesis acabadas durante el año de 1954, fué presentada ya a la Facultad la de la señorita Yamuni, Procesos discursivos en pensadores de lengua española comparados con pensadores de otras lenguas. Representa la segunda parte de su amplio plan de trabajo. La investigación de las formas de pensar de los pensadores contemporáneos de lengua española empezó por las más obviamente tales, los procesos discursivos, pero pronto descubrió que había, por un lado, que retroceder hacia los elementos de los procesos discursivos que son los conceptos y que tendría, por otro lado, que proceder del estudio de los procesos discursivos al de los motivos alógicos del pensamiento. Incluso se avizoró que la investigación de las formas de pensar no daría resultados del todo concluyentes sin una investigación complementaria de los temas y eventuales sistemas de los pensadores. El estudio de los conceptos condujo 
al de las imágenes, en varios sentidos. Los conceptos que mientan objetos por medio de las relaciones metafóricas y metonímicas de éstos con otros, y los que mientan objetos susceptibles de serlo simultáneamente de imágenes psíquicas de peculiar plasticidad, se revelaron de una importancia muy especial en el discurso del pensamiento que tenía su expresión en los textos elegidos. Estos fueron de Martí, Rodó, Unamuno, Ortega y Vasconcelos. Los mismos son los estudiados también en esta tesis sobre los procesos discursivos, pero en esta tesis se impuso ya la comparación con pensadores de otras lenguas: los textos elegidos fueron de Bergson, Marcel, Whitehead y Dewey. La elección resultó de la confluencia de unas circunstancias y un criterio. Los textos tenían que ser estudiados en la lengua original, y las lenguas extranjeras y pertinentes conocidas de la autora eran el francés y el inglés. Y los textos que se eligiesen debían ser lo más a propósito posible para la comparación con los de lengua española ya elegidos. Los resultados de la investigación están presentados muy exactamente por la autora en las siguientes palabras de su prólogo: "Los resultados que presenta esta tesis son de dos clases. Unos se refieren al fin más propio de la tesis y de todo el plan. Son los resultados de caracterización de los textos estudiados por sus procesos discursivos." "Los otros resultados son más generales. Son los resultados del análisis y clasificación de los procesos. Estos resultados versan sobre el pensamiento en general. Y como caen bajo las tres grandes clases del ser y no ser, los todos y las partes, y las clases de causas, versan, algo por lo menos, sobre los principales temas de la filosofía." Para poder caracterizar los textos por los procesos discursivos de los que son expresión, era indispensable llevar a cabo la previa labor de descomponer los discursos de pensamiento expresados por los textos en los procesos discursivos que debieran considerarse como elementales, tratar de definir la índole de cada uno de ellos y clasificarlos conforme a la índole de cada uno en las clases ascendentes que así se ofrecieran. El resultado final fué la reducción de todos los procesos elementales discernidos a los tres grandes grupos mencionados en las anteriores palabras de la autora. Procesos de ser y no ser llama ésta a las definiciones y a otros procesos en la expresión de los cuales entra el verbo ser, o un sinónimo de éste, o alguna forma de negación, y también a procesos a los que se pasa sin solución de continuidad desde los de negación, a saber, las antítesis. Por procesos de todos y partes entiende los que discurren de todos a partes, o viceversa, trátese de todos y partes concretos o abstractos. La autora distingue la "partición" y la "totalización", que discurren entre concretos, y la "especialización”, "individuación", "especificación” y "generalización”, que discurren entre términos de los que uno por lo menos es de índole específica o genérica. En esta clasificación se aprovecha la dualidad de los términos "especialización" y "especificación" para distinguir entre el paso de géneros a especies o entre especies y el de individuos a especies. EI tercer gran grupo de procesos es el de los que discurren de causas a efectos, o vice- 
versa, tomando los términos de causa y efecto en el sentido más amplio posible, o de la causalidad eficiente, final, formal, ejemplar, instrumental, con lo que entran en el grupo los procesos de fundamentación, también en el sentido más amplio posible de este otro término. "Todos estos resultados vienen a ser de fenomenología del pensamiento", dice también muy exactamente en el mismo lugar la autora. Y de una fenomenología que ha sido traída por los fenómenos mismos, de una parte, a hacer en ellos distinciones no hechas, o no hechas como se hacen en esta tesis, con los consiguientes análisis y descripciones de la congruente novedad; $y$, de otra parte, a abocarse, siquiera, a algunos de los más importantes, actuales -y eternos- problemas de la filosofía. De ejemplo de aquellas distinciones pueden servir las hechas en los procesos de causalidad. Por la literatura filosófica andan revueltos procesos tan diferentes como los considerados de causación de objetos reales por otros también reales, de objetos ideales por los actos intencionales correspondientes y de éstos por sus objetos ideales -sin ser ésta la única revoltura semejante, ni mucho menos-. Como ejemplo de los problemas a que se aboca la tesis puede tomarse el problema más conspicuo por su actualidad, el de la función de la negación en el pensamiento y el del alcance o fundamento objetivo de esta negación. Los resultados cuasi estadísticos presentados por la tesis prueban documentalmente, con una concreción y detalles según todas las noticias nuevos, en qué significativa proporción se piensa por distinción o diferenciación, oposición y negación, quizá en contra de la tradicional preferencia del pensamiento filosófico por la generalización. Los resultados de esta clase fenomenológica se utilizan luego para caracterizar comparativamente los textos. Los resultados de esta otra clase los caracteriza, a su vez, la autora con estas otras palabras del mismo prólogo: "se parecen, sobre todo, a los de la estilística. Así como ésta caracteriza el estilo literario de los autores por los procedimientos estilísticos, esta tesis caracteriza lo que se puede llamar el estilo mental de sus textos por sus procesos discursivos". Aunque de estos resultados unos comprueban documental y analíticamente juicios que antes de semejante comprobación no pasaban de enunciar "impresiones", y otros son nuevos y hasta sorprendentes, el jurado encargado de examinar la tesis estimó que en el curso de las investigaciones de la señorita Yamuni se había invertido la relación de valor entre las dos vertientes de ellas: lo en un principio sólo instrumental, la fenomenología del pensamiento en general, ha acabado por prevalecer justificadamente sobre lo que al comienzo fué el fin determinante de las investigaciones, la caracterización de las formas de pensar de los pensadores contemporáneos de lengua española. Así, habrá la tesis de dar a sus dos ingredientes las relativas proporciones debidas, sin menoscabo de la continuación del plan de que es parte. La exploración de los motivos alógicos del pensamiento no promete, precisamente, resultados menos interesantes ni importantes.

Las otras dos tesis acabadas durante el curso no lo han sido a tiempo 
de ser presentadas a la Facultad dentro del año académico ordinario. Lo serán en un período de exámenes extraordinarios o en cuanto se abra el año académico próximo.

La acabada primero versa sobre los eclécticos portugueses del siglo xvm y algunas de sus influencias en España y América. Con ella continúa, pues, su autora, la señorita Carmen Rovira, el estudio del eclecticismo de los siglos xvII y xvm iniciado por la señorita Junco y el desarrollado amplia y decisivamente por el señor Navarro y la señorita Quiroz-Martínez. Los eclécticos portugueses estudiados son Verney y los PP. Almeida, del Oratorio, y Monteiro, de la Compañía de Jesús. El haberse dirigido a ellos inmediatamente después de haberse ocupado con los mexicanos y españoles no se debió a razones de proximidad geográfica o cultural, sino a la decisiva razón de la importancia del primero de ellos para la historia ideológica de España y de los países hispanoamericanos: en este punto es el Barbadiño émulo, el único, de Feijóo. Las polémicas españolas en torno al Verdadero método de estudiar no ceden en nada a las polémicas en torno a la obra de Feijóo. Lo que a Verney debe Gamarra es más aún de cuanto ya había visto la señorita Junco. Y, según todas las apariencias a través de Gamarra, viene a ser lo mismo lo que le debe el cubano P. Caballero, con lo que el papel de Verney en la introducción de la filosofía moderna en Cuba resulta tan considerable como en México. Y el Nuevo Luciano de Quito del ecuatoriano Espejo no es sino una réplica del Verda: dero método. La tesis de la señorita Rovira expone estas polémicas e influencias después de resumir, en términos más generales, la posición de los tres autores portugueses en punto a "concepción del mundo y de la naturaleza", "filosofía, razón y conocimiento", "educa ción", "literatura, retórica, poesía, oratoria sagrada", "ética, derecho", "teología, religión", "historia", y, especialmente, en sendos capítulos, su física, lógica y metafísica. Las páginas de la tesis recorren, pues, un sector realmente céntrico del ideario de la Ilustración iberoamericana. Las conclusiones inferidas confirman en lo esencial la visión de esta Ilustración obtenida por los anteriores trabajos sobre el eclecticismo de aquella época: la peculiar "modernidad cristiana" que se la ha llamado. La señorita Rovira se propone continuar todavía el estudio del mismo eclecticismo con el de los autores italianos. La importancia de éstos para los hispanoamericanos es suma, por obra en general de las relaciones existentes entonces entre los países hispánicos e Italia, y especialmente de la expatriación de los jesuítas a tierras itálicas.

La última tesis acabada durante este año es la de D. Fernando Salmerón sobre las mocedades de Ortega y Gasset, es decir, sobre la obra de éste correspondiente al período denominado por él mismo con tal término. Deber, hay que decir, de un seminario dedicado al estudio del pensamiento en los países de lengua española es componer sendas monografías sobre los principales representantes de este pensamiento, y en primer término sobre los contemporáneos. Las monografías compuestas sobre los filósofos de otras lenguas, y 
no sólo sobre los principales, son aportación capital a lo que puede llamarse la refundición continua de la historia de la filosofía por la Historia de la Filosofía que decide de los valores filosóficos en la historia. A la insuficiencia, en número y en calidad, de monografías sobre los pensadores de nuestros países debe atribuirse, pues, en buena parte la inadecuada, cuando no francamente injusta, valoración de ellos y el desconocimiento de los mismos fuera de los respectivos ámbitos nacionales, o poco más, salvo raras excepciones. Pero al seminario no le fué dado empezar a cumplir con este deber hasta que entró en él el señor Salmerón animado de una previa devoción por la obra de Ortega y poseedor de un notable conocimiento de ella. El señor Salmerón representaba la posibilidad de escribir aquella obra sobre Ortega que aún no se ha publicado y hace falta creciente para situar la polémica sobre el maestro y la crítica apolémica de él en el nivel debido. Y lo primero era llevar a cabo el inventario riguroso de los temas de Ortega. Antes de saber con toda precisión de las variadísimas cosas de que ha escrito Ortega temática o incidentalmente, insistentemente o por una vez, seguirán careciendo de la base requerida las discusiones acerca de la originalidad de la filosofía de Ortega y las disquisiciones en torno a su significación propia e histórica. La forma misma de la obra de Ortega imponía al inventario empezar siguiendo el orden cronológico de las publicaciones de éste; el orden de composición siempre que fuera posible fijarlo. Pero la forma de darse a lo largo de las publicaciones de Ortega sus temas, como los de una gran sinfonía o, incluso, los de una "polilogia” a la wagneriana, apareciendo, desapareciendo, reapareciendo, como leit-motive, como motivos esporádicos, y la finalidad propia de un inventario, el registro ordenado de los correspondientes objetos, fueron enderezando los resultados que iba obteniendo el señor Salmerón hacia una sistematización. que en ningún caso debía rebasar los límites más allá de los cuales sería infiel a un pensamiento tan asistemático, al menos en su forma de "producirse". Por lo demás, el material recolectado tan sólo en el período de las mocedades resultaba tan abundante, que fué forzoso limitar a él una primera parte del trabajo y una primera tesis. Esta examina sucesivamente los siguientes grandes temas: "El problema de España", "El tema de la cultura", "La filosofía, la ciencia y el método", "El arte y la crítica", "La idea de la vida", "La idea de la historia", "El hombre y la sociedad", "El tema de Dios; la religión y la fe", "Los temas metafísicos: las cosas, la realidad". El orden de estos temas va en general de los patentemente predominantes en la preocupación de Ortega durante sus mocedades hasta aquellos cuyo interés estriba más que en su importancia dentro del período, en lo que tienen de antecedentes de los filosofemas más orteguianos de los períodos posteriores. El examen de cada uno de los temas sigue el desenvolvimiento del tema a través de la producción cronológicamente ordenada del período, pero procuró y ha logrado sin violencias, por renunciar a ir más allá del límite donde hubieran empezado, articular las vicisitudes de cada tema entre hitos cardinales. He aquí los de cada 
tema. España: Casticismo.-Europeísmo.-Germanismo. Cultura: España y la cultura. La beatería.-El pathos del sur y la cultura germánica. Arte: Personalismo.-La crítica objetiva.-La madurez de las ideas estéticas.-Ultimas variaciones. Historia: Los terrores del año mil.-La historia europea, la ruta de la historia.-El héroe y la historia.-El método de la historia.-Otros temas menores, Hombre y sociedad: Masa y minoría selecta.-La nación.-El nacimiento del hombre.-La virtud política: el socialismo.-Lo individual, lo íntimo, lo subjetivo es el error.-La pedagogía social. Dios: Defensa del místico frente al teólogo.-Teoría de la religiosidad.-La ciencia y la fe.-El Dios de Renán. Pedagogía y religión. El ser: Las primeras imágenes metafísicas.-El ser de las cosas. Los objetos (kantismo).-Substancia y relación. La idea de la vida. Se han dejado los temas de la ciencia y de la vida para dar una idea más detallada del examen de los temas en general, en palabras del propio autor de la tesis, escritas para este informe. El tema de la ciencia es capital en las mocedades de Ortega, dominadas por un peculiar ciencismo. Del tema de la vida, el esencial del Ortega de la madurez, interesan singularmente los antecedentes juveniles. La ciencia: “A. La ciencia española. (1902) Defensa del método personalista. (1906) La ciencia española es un hecho personal y no una acción social. Es ciencia indisciplinada, fanfarrona y mística, ciencia que gana sus verdades a saltos, por vías sentimentales, por instinto y no por labor de raciocinio. Es lo más opuesto de la ciencia disciplinada de Francia y Alemania, que por lo demás no es deseable en España, porque acabaría haciéndonos otros'-B. La ciencia europea. ¡Salvémonos en las cosas! (1908) En España no ha habido ciencia, ha habido uno que otro hombre científico por casualidad, pero ciencia no; han faltado las matemáticas y la filosofía, que son el centro de la cultura moderna. En estos años Ortega, ciencista creciente y defensor del rigor y de la disciplina, disputa por estos motivos con varios contemporáneos. Rechaza a los hombres de ciencia y filósofos a quienes la literatura pudo dañar la conciencia científica. El rigor y el sistema son los criterios de la veracidad de las doctrinas. Defensa de la ciencia y de sus métodos en contra de la fe. Llamado a los españoles para olvidar las preocupaciones personales, porque lo subjetivo es el error. Lo objetivo es lo verdadero. $-C$. Sin que desaparezcan estas últimas ideas, Ortega hace en estos años una teoría de lo verosímil. $-D$. Hace igualmente una doctrina del punto de vista.-E. Discute los problemas de las relaciones entre la ciencia y la vida y el lugar de la ciencia en el sistema de las actividades humanas (1910). $-F$. (1911) Belaciones de la verdad y las circunstancias.-G. La verdad y la perspectiva histórica. El progreso científico.-H. (1913) Descubrimiento de la fenomenología y adhesión entusiasta al método."-La vida: "A. La intuición fundamental. (1902) Desde el primer artículo de Ortega, escrito a los diecinueve años, aparece este concepto. $\mathrm{El}$ artículo, en medio de toda la imprecisión que aún tiene en este punto, encierra ya la intuición fundamental del filósofo: nuestra vida, la de cada uno de nosotros, es la realidad básica a la que no es posible vol- 
ver la espalda. $-B$. La vida nacional y las primeras influencias idealistas. (1906) Acosado por los problemas colectivos, Ortega empieza a hablar de la vida nacional, la vida española, y en ésta se disuelve y se pierde la vida individual. La insignificante vida individual sólo cobra valor si se apoya en los grandes problemas universales, en la Vida Universal. A partir de este momento, ni una sola frase sobre la vida individual: la del autor tiene intención filosófica.-C. La metafísica de la vida. (1908) Bajo la influencia de Nietzsche, vuelve el tema de la vida como fuerza y voluntad de poderío. (1909) Gran entusiasmo por la idea de la vida, en que Ortega dice descubrir grandes posibilidades de desarrollo en sentido metafísico. (1910) Madurez de esta metafísica de la vida y exposición de una visión sistemática del universo. Identificación de la Vida y el Ser. La vida de una cosa es el sistema de relaciones que la integran y que la ciencia trata de determinar.-D. La fuerza vital. (1911) Las ideas anteriores desaparecen muy rápidamente. La influencia de los maestros idealistas que ven en la experiencia de la vida algo secundario, sigue fomentando un desdén uniforme en estos años por la vida individual. Bajo la influencia de Worringer, predomina la vida en sentido biológico como actividad, energía, poder. Sin embargo, no deja de hablarse de la vida española. Y se pone en relación la vida humana individual con la Vida Universal de que antes se ha hablado: la tragedia de la primera consiste en no poder abarcar a la segunda en su totalidad. Pero las afirmaciones sobre la vida individual siguen en el plano de la confesión personal, sin unidad ninguna y sin pretensión de explicar nada." La tesis contiene, además del examen de temas de que se acaba de dar idea, otras dos cosas. La obra de Ortega ha sido en general de origen y temas "circunstanciales", pero esta afirmación es válida doblemente de su parte inicial. La mejor comprensión de esta parte requiere un conocimiento de su circunstancia española que no cabe suponer ni siquiera en el término medio de los posibles lectores hispanoamericanos de la tesis. Por esta razón antepone la tesis al examen de temas un panorama de "la situación de España", que, aunque no sea fruto de investigaciones propias del señor Salmerón, será de indudable utilidad al término medio de los lectores. El autor de la tesis hubiera querido incluir ya en ésta los resultados de la investigación de las fuentes del pensamiento de Ortega. Pero la investigación de las fuentes extranjeras, principalmente las alemanas, tropezó con dificultades que la han aplazado hasta este momento. Por otra parte, el volumen de la tesis rebasa el prudente en atención a consideraciones editoriales. El autor se ha limitado, pues, en este volumen, a dos puntos. Dedica una sección a tratar de los que el joven Ortega mismo llama sus maestros, españoles, y otra sección a tratar de los críticos de aquel joven que ya llamaba tanto la atención y forzaba a tomar posición relativa a las suyas. En conclusión, que a la perseverancia orteguiana del señor Salmerón aguardan aún bravas faenas: en el espectador que fué Ortega desde un principio, desde entonces "nuestro tiempo gozaba en reflejarse con pasmosa precisión" (Ortega sobre Scheler). 
Prácticamente conclusa puede considerarse la exposición que el peruano D. Manuel Mejía ha venido componiendo del positivismo en su país. Lo que está en trance de añadirle no es sino un complemento final y algunas adiciones y mejoras intercalares. Esta exposición extiende, al cabo de los años, la primera dirección de la labor del seminario desde México hasta el Perú, donde el positivismo, si no ascendió a filosofía oficial de un régimen, cuenta con algunas de las figuras preeminentes en la historia entera del pensamiento nacional. La exposición abarca desde las primeras noticias del positivismo en el Perú por 1859, hasta la superación del mismo en la obra de Deústua, tan paralela por las influencias sobre ella y de ella a la de los maestros mexicanos del Ateneo de la Juventud. En el intermedio destacan las figuras de GonzálezPrada y Cornejo como conviene a su relieve internacionalmente reconocido, pero las rodean otras figuras de más o menos relieve nacional, si no tan conocidas internacionalmente, como las de Javier Prado, Isaac Alzamora, Federico Villarreal, Carlos Wiesse, Manuel Vicente Villarán, y noticias sobre hechos intelectuales y académicos que acaban de pintar un cuadro de subida concreción histórica. El seminario ha acogido en varios casos a estudiantes iberoamericanos becarios de El Colegio de México para componer tesis destinadas a Universidades de los países de origen, o trabajos no destinados a ser presentados como tesis, pero de índole afín a la de las tesis.

Las tesis continuadas durante el presente año son dos. Con la empezada primeramente se persigue una de las mayores ampliaciones de la labor del seminario: pasar de la Historia resueltamente a la Filosofía, aunque por vía de la disciplina filosófica más cercana por su objeto a los objetos tratados anteriormente en el seminario. La señorita Elsa Cecilia Frost acometió la empresa de componer un ensayo de filosofía de la cultura mexicana, intentando prolongar la línea de trabajos que puede considerarse iniciada por El perfil del hombre y la cultura en México, del Dr. Samuel Ramos, y que se convirtió en estos años pasados en todo el volumen de la "filosofía del mexicano", hasta el término más sistemáticamente cabal posible. Ante todo, había que fijar el estado de la Filosofía de la Cultura, y singularmente el concepto mismo de ésta, ya para plantear correctamente el problema de la posibilidad de la filosofía de una cultura determinada. Simultáneamente se podía ir recogiendo los conceptos aplicados a la cultura mexicana con intención de situarla o caracterizarla -como "indoibérica", "mestiza"-, para precisar su sentido y su posible contribución a una interpretación filosófica de la cultura mexicana. Son las dos tareas ya rematadas por la señorita Frost. Esta debe ahora iniciar la que le dará como resultado el torso de su tesis: el análisis, bajo los puntos de vista fijados por las conclusiones relativas a la Filosofía de la Cultura en general, de productos o manifestaciones representativas por excelencia de la cultura mexicana en sus diversos sectores y en lo que se presenta conjugadamente como más valioso y más peculiar de ella.

La historia de las ideas estético-literarias en México durante el siglo xIx 
es el tema de la tesis continuada durante el presente año por D. Francisco González Aramburo. Las fuentes a que éste recurre no son sólo las publicaciones de crítica e historia literaria - de estética propiamente tal hay muy poco-, sino también las obras literarias. La investigación comenzó por Altamirano, centro del nacionalismo literario, movimiento central a su vez en la literatura mexicana del siglo pasado. Dentro de los puntos de vista sugeridos por el estudio anterior, pudo mantenerse aún el de Vigil, pero ya no el de Ramírez, Pimentel y Roa Bárcena. Ramírez impuso considerarlo como el "ejemplo singular" que es "de clasicista que niega todo idealismo y se apoya firmemente en una concepción sensualista-materialista de lo bello". Pimentel y Roa Bárcena se encontraron incursos en "la última manifestación del neoclasicismo: el eclecticismo". De los teóricos del clasicismo pasó la investigación a la de los "creadores" del mismo, Carpio, Pesado; Navarrete. La del romanticismo no ha pasado aún de "las noticias que dan las historias de la literatura, sus enemigos los neoclásicos y sus tibios defensores, los eclécticos", y de las poesías de Rodríguez Galván. El orden anterior responde a aquel en que el señor González Aramburo pudo ir teniendo acceso a las fuentes.

Las tesis iniciadas en 1954 son, por orden de iniciación, una exposición de la filosofía de Jaspers, por D. Alejandro Rossi, otra del existencialismo italiano, por D. Pedro Duno, y un estudio crítico de las relaciones entre conciencia y existencia en Heidegger, por la señora Rosario Gamboa. Con ellas el seminario añade al estudio del pensamiento de lengua española el de la filosofía contemporánea de otros países. Ello ha sido consecuencia del traslado del seminario desde El Colegio de México hasta la Facultad -sin dejar de ser patrocinado por El Colegio-, consecuencia a su vez de la nueva situación creada por el traslado de la Universidad a la Ciudad Universitaria y por las obligaciones del profesorado de carrera. Para responder satisfactoriamente a esta nueva situación, resultaba indispensable acoger en el seminario a quienes prefieren a los temas de pensamiento hispánico otros temas. Estos se han limitado por lo pronto a la filosofía contemporánea. Los filósofos de nuestros días atraen preferentemente, por su interés de actualidad y por la mayor novedad del ocuparse con ellos que con los clásicos, tratados y architratados. Por lo demás, los mayores filósofos de nuestros días, con certidumbre "clásicos futuros", pueden prestar a la formación filosófica servicios parejos a los prestados siempre por los clásicos del pasado. La posibilidad de lograr obras sobre ellos con interés por los temas y méritos por la forma para entrar en la circulación internacional, es un incentivo para esforzarse por realizarla. En otros respectos, aconsejaban la limitación otras de los aspirantes a trabajar en el seminario y del encargado de éste: las lenguas poseídas por los primeros, la trayectoria de los trabajos propios y la competencia del último. Nada más que lo que se acaba de decir debe decirse de las tres tesis. Están, aun la iniciada primeramente, demasiado en los primeros pasos, para que sea prudente añadir nada sobre ellas. La experiencia ha enseñado que mientras una tesis no está 
relativamente muy avanzada, no puede considerarse asegurada en ningún sentido. En rigor, ni siquiera estando tan avanzada como para estar prácticamente concluída... Las tesis reseñadas o citadas en este informe distan de ser las únicas, no ya proyectadas o iniciadas y abandonadas o interrumpidas -también el año 1954-, sino compuestas del todo en el seminario. Compuestas del todo, o muy poco menos, y hace ya años, las del señor Rafael Moreno sobre los periódicos mexicanos del xvir y sobre Feijóo, la del señor Augusto Salazar Bondy sobre su compatriota Unanue y la Ilustración peruana, no han sido las primeras ni siquiera presentadas a la Facultad, sin que quien las dirigió sepa las razones; la última, presentada a la Universidad de San Marcos, publicada, al menos que sepa quien esto escribe.

El seminario ha venido funcionando regularmente en reuniones semanales o quincenales de una hora del profesor con cada uno de los demás miembros. Este da cuenta a aquél del trabajo hecho durante la semana o quincena, el profesor hace sus observaciones, y ambos fijan de común acuerdo el trabajo de la semana o quincena siguiente. La experiencia ha enseñado que la mejor periodicidad de las reuniones es la quincenal. Ocho días son poco tiempo para traer resultados suficientes a la reunión. Las reuniones mensuales resultan demasiado pocas en el curso del año académico, y las reuniones demasiado espaciadas en general mueven a la intermitencia y a la irregularidad en un trabajo al que favorece como nada la continuidad paulatina. Pero las reuniones se multiplican y alargan cuando resulta necesario, sin más límites que los de la necesidad: es lo sólito en el último período de composición de las tesis.

La experiencia ha enseñado también que la composición de tesis pasa por dos crisis psicológicas y tres fases de trabajo. A poco de iniciarse éste sobreviene la decepción acerca del tema, por lo poco que éste da de sí. Se quiere cambiar de tema, en la ilusión de que otro será más fértil. Pero todos los temas son durante una primera temporada igualmente áridos y por las mismas causas. El conocimiento de los hechos del tema, las ideas acerca de éste, las hipótesis de trabajo con que se lo aborda son, naturalmente, magros. Los primeros pasos son los más difíciles, aquí como en el milagro de San Dionisio, que cogiendo la cabeza que le habían cortado, echó a andar. Consisten en ir tras de libros y documentos, en hacer extractos y papeletas... y no se sabe aún trabajar bien. El trabajo no aporta resultados atractivos ni en sí mismo da satisfacciones. Antes de poner término a la composición de la tesis se produce una crisis de signo inverso. La realidad sobre la que se trabaja de veras se detalla, se multiplica, se acumula, desborda. El trabajador no sabe qué hacer con el material cosechado y se desespera. Habla de tirarlo todo de una buena vez por la ventana y quedar en paz. Queda, naturalmente, mucho más en paz si, dócil por segunda vez a las observaciones entre irónicas y cordiales, y autorizadas por la experiencia, del profesor, que no puede menos de ser en ambas ocasiones un curioso espécimen de incipiente psiquiatra intelectual, impone al material selección y orden y lleva tanto esfuerzo a buen 
término. Las fases de trabajo por las que pasa la composición de las tesis no son estrictamente cronológicas. En cada etapa, por no decir en cada momento, del proceso de composición, pueden, por lo menos, darse las tres; pero cada una de ellas predomina notoriamente sobre las otras dos en sucesión tan determinada como lógica. Al predominio de la pura recolección de material sigue el de la selección y ordenación, el de la composición en el sentido más propio y estricto, para ceder al de la redacción. En la recolección de material no entran sólo actividades como las motivantes de la primera crisis: acaban por entrar operaciones de la mayor finura y hondura intelectual, como las requeridas por el análisis y la interpretación de textos y por la ordenación paulatina y provisional del material, pues la ordenación de éste no debe aplazarse íntegramente hasta la fase de la composición en sentido estricto y propio, so pena de no superar la segunda crisis. De hacerlo así es el procedimiento práctico ir redactando trabajos parciales y provisionales: la lectura por los autores y la crítica por el profesor es entonces el contenido de las reuniones. En la ordenación del material y la composición en el repetido sentido es la norma metodológica esencial no imponer al material cuadros preconcebidos, sino esforzarse por organizarlo según las articulaciones sugeridas por él mismo -sobre el supuesto de que la realidad no es amorfa, sino que tiene formas que no dejarían de ser propias de ella por oriundas de la subjetividad de que lo fueran. En la composición se da una zona de tránsito de la ciencia al arte que no todos tienen interés en franquear ni aptitudes para franquearla. A quienes tienen éstas y aquél les plantea la redacción un problema estilístico -cuando las aptitudes no son tamañas para resolver, esto es, satisfactoriamente, el problema sin planteárselo, esto es, espontáneamente-. La cooperación del profesor a la composición de las tesis es diversa según las fases del trabajo, como de suyo se comprende. Sugerir temas y aconsejar en la elección, según los conocimientos e inclinaciones, aptitudes y preferencias de la persona. Hacer las primeras indicaciones acerca de fuentes de material y acerca de la manera de beneficiarlas. Sobre todo, ayudar a plantear el tema $-o$, por lo general, a limitarlo: la mayoría empieza por temas muy vastos, en parte por temor a no tener material bastante: la experiencia dice que el comportamiento de la realidad bajo el trabajo obliga a ir limitando el tema inicial hasta una parcela de él que al principio se hubiera rechazado por ridícula - por lo que lo mejor es en estos casos aguardar a que el curso del trabajo fuerce al trabajador mismo a limitar con ganas y gusto su tema. A poco de haber empezado de veras la recogida de material, quien va recogiéndolo comienza a saber del asunto mucho más que el profesor. La cooperación de éste se reduce entonces a ir cuidando de que el trabajo se ajuste continuamente a las debidas normas metodológicas y a suministrar ideas y noticias de la circunstancia en torno, a menos o más distancia, del tema mismo de la tesis. En particular, es el profesor el brgano de comunicación de los resultados obtenidos por los demás miembros del seminario entre éstos mismos: quien está en el punto de convergencia, o divergencia. 
de los trabajos, es el más capacitado para comunicar a los unos lo que puede aprovecharles de lo conseguido por los otros. Quizá el momento en que la cooperación del profesor es más decisiva, es el de la composición propia y estrictamente tal. La tendencia a la cómoda imposición al material de cuadros que ya están ahí o por ahí, suele requerir alguna pugna para lograr el esfuerzo de exprimirse la sesera hasta ver las formas propias de la realidad misma y articular el material conforme a ellas. Finalmente, el profesor revisa hasta la redacción última, pero interviniendo en ella tan diversamente como aconsejan los diversos talentos de escritor de los autores. Pero las tesis se publican -por El Colegio de México- siempre más o menos refundidas de acuerdo con las críticas, demandas, sugestiones hechas por los señores miembros de los jurados que las examinan. La duración de la composición de las tesis depende mucho menos del trabajo exigido por ellas que de la concurrencia de otros trabajos, escolares o ya el profesional. La composición de la mayoría de las tesis acabadas ha durado tres o cuatro años. Los señores Zea y Villoro acabaron la composición de las suyas en sendos años. A lo largo de cinco se prolongó la composición de la segunda de la señorita Yamuni.

JosÉ GAOS 